\title{
Locked and loading megathrust linked to active subduction beneath the Indo-Burman Ranges
}

\author{
Michael S. Steckler ${ }^{1 \star}$, Dhiman Ranjan Mondal ${ }^{2,3}$, Syed Humayun Akhter ${ }^{4}$, Leonardo Seeber ${ }^{1}$, \\ Lujia Feng ${ }^{5}$, Jonathan Gale ${ }^{1}$ Emma M. Hill ${ }^{5}$ and Michael Howe ${ }^{1}$
}

\begin{abstract}
The Indo-Burman mountain ranges mark the boundary between the Indian and Eurasian plates, north of the Sumatra-Andaman subduction zone. Whether subduction still occurs along this subaerial section of the plate boundary, with $46 \mathrm{~mm} \mathrm{yr}^{-1}$ of highly oblique motion, is contentious ${ }^{1-8}$. About $21 \mathrm{~mm} \mathrm{yr}^{-1}$ of shear motion is taken up along the Sagaing Fault, on the eastern margin of the deformation $z o n e^{8,9}$. It has been suggested that the remainder of the relative motion is taken up largely or entirely by horizontal strike-slip faulting and that subduction has stopped $3,5,7,10$. Here we present GPS measurements of plate motions in Bangladesh, combined with measurements from Myanmar ${ }^{9}$ and northeast India ${ }^{10}$, taking advantage of a more than $300 \mathrm{~km}$ subaerial accretionary prism spanning the Indo-Burman Ranges to the Ganges-Brahmaputra Delta". They reveal 13-17 $\mathrm{mm} \mathrm{yr}^{-1}$ of plate convergence on an active, shallowly dipping and locked megathrust fault. Most of the strike-slip motion occurs on a few steep faults, consistent with patterns of strain partitioning in subduction zones. Our results strongly suggest that subduction in this region is active, despite the highly oblique plate motion and thick sediments. We suggest that the presence of a locked megathrust plate boundary represents an underappreciated hazard in one of the most densely populated regions of the world.
\end{abstract}

India started colliding with Eurasia in the Eocene epoch ${ }^{12}$, creating the Himalayas and Tibet. The plate boundary bends around an eastern syntaxis in Assam into the Naga thrust belt (Fig. 1). It continues southwards into the Indo-Burma foldbelt and Andaman-Sumatra subduction zone, transitioning from continental collision to oceanic subduction. The highly oblique convergence of the Indo-Burman segment has led to partitioning among shortening structures, such as thrust-folds, and purely dextral faults. The easternmost is the Sagaing Fault ${ }^{8,9,13}$, which absorbs $\sim 20 \mathrm{~mm} \mathrm{yr}^{-1}$ of dextral motion and is usually considered the eastern boundary of a Burma platelet ${ }^{1,8,9,11}$

In the Bengal Basin, the crust of the Indian Craton thins southeastwards across the hinge zone of an Early Cretaceous continental margin ${ }^{11,14}$ (Fig. 1). The thin continental and/or oceanic crust of the Bengal Basin is overlain by the southeast prograding Ganges-Brahmaputra Delta (GBD) formed at the confluence of these two great Himalayan rivers. They have supplied copious amounts of sediment (at present $>1 \mathrm{GT} \mathrm{yr}^{-1}$ ) that has prograded the continental shelf by $300-400 \mathrm{~km}$ since the Eocene ${ }^{11,15}$. The delta has also depressed the underlying crust with $16-20 \mathrm{~km}$ of sediment ${ }^{16}$. The boundary between thinned, rifted continental crust and oceanic crust beneath the GBD is unknown, although $\sim 200 \mathrm{~km}$ east of the hinge zone Mitra et al. ${ }^{17}$ identified an oceanic signature beneath $21 \mathrm{~km}$ of sediment in a receiver function at the outer fold belt.

The GBD is overthrust from the north across the Dauki Fault by the Shillong Massif, a 2-km-high basement-cored anticlinorium that depresses the adjacent $\mathrm{GBD}^{18}$. This thrusting may represent a forward jump of the Himalayan front ${ }^{19}$. On the east side of the GBD, the 1,400-km-long Indo-Burman Ranges (IBR) are the surface expression of an extremely wide forearc $(500 \mathrm{~km})$ and accretionary prism $(250 \mathrm{~km})$. The slab is illuminated by earthquakes to depth $>150 \mathrm{~km}$ (ref. 20). The eastern Indo-Burman Ranges are the remains of a west-verging Palaeogene subduction complex $^{21}$ that may now be the backstop of the forearc. West of the Churachandpur-Mao Fault (CMF; Fig. 1) is a $\sim 250-\mathrm{km}$ wide Neogene accretion belt, strongly influenced by Himalayan sediment input ${ }^{22}$. The accrual of the thick sediments of the GBD and Bengal Basin has built this enormous accretionary prism, which represents an endmember in several respects ${ }^{1,11,16}$. The outer folds extend below the GBD and are blind, buried by the rapid sedimentation $^{23,24}$ (Fig. 1). The prism is the world's flattest $\left(0.1^{\circ}\right)$, indicating a weak detachment ${ }^{11}$. Absorbing the great sediment thickness of the Bengal Basin, the prism is subaerial for several hundred kilometres along strike and, in parts, densely populated. Despite the unusual exposure and significance for hazard, little is known about this subduction boundary, or even if it is still active.

We installed a suite of 26 continuous GPS receivers between 2003 and 2014, covering the mostly deltaic country of Bangladesh. We focus on the 18 stations with a $6-10$-yr time series. GPS data from Bangladesh cover the frontal region of this unusual subaerial prism, while observations from India and Myanmar provide velocities for more internal parts of the boundary (Fig. 1). We use the velocities in India published by Gahalaut et al. ${ }^{10}$, consisting of 5 continuous and 23 campaign stations occupied annually from 2004 to 2011 . We use stations south of the latitude of Shillong Massif only. To investigate the Sagaing Fault farther east, we use the campaign network in Myanmar occupied in 2005 and 2008 ${ }^{9}$. These data encompass the entire plate boundary zone and can be used to determine the total current plate motion and how it is distributed between purely dextral and possible convergent motion.

Our results show $46 \mathrm{~mm} \mathrm{yr}^{-1}$ of highly oblique motion between peninsular India and the Shan Plateau. This is larger than the $36 \mathrm{~mm} \mathrm{yr}^{-1}$ India-Sunda velocity ${ }^{25}$, probably due to toroidal flow from Eastern Tibet $^{7}$ in this non-rigid region. This motion includes $18 \mathrm{~mm} \mathrm{yr}^{-1}$ of convergence across the boundary and $42 \mathrm{~mm} \mathrm{yr}^{-1}$

${ }^{1}$ Lamont Doherty Earth Observatory of Columbia University, Palisades, New York 10964, USA. ${ }^{2}$ School of Earth and Environmental Sciences, Queens College, City University of New York, Flushing, New York 11367, USA. ${ }^{3}$ Earth and Environmental Sciences, Graduate Center, City University of New York, New York, New York 10016, USA. ${ }^{4}$ Department of Geology, Dhaka University, Dhaka 1000, Bangladesh. ${ }^{5}$ Earth Observatory of Singapore, Nanyang Technological University, Singapore 639798, Singapore. *e-mail: steckler@ldeo.columbia.edu 


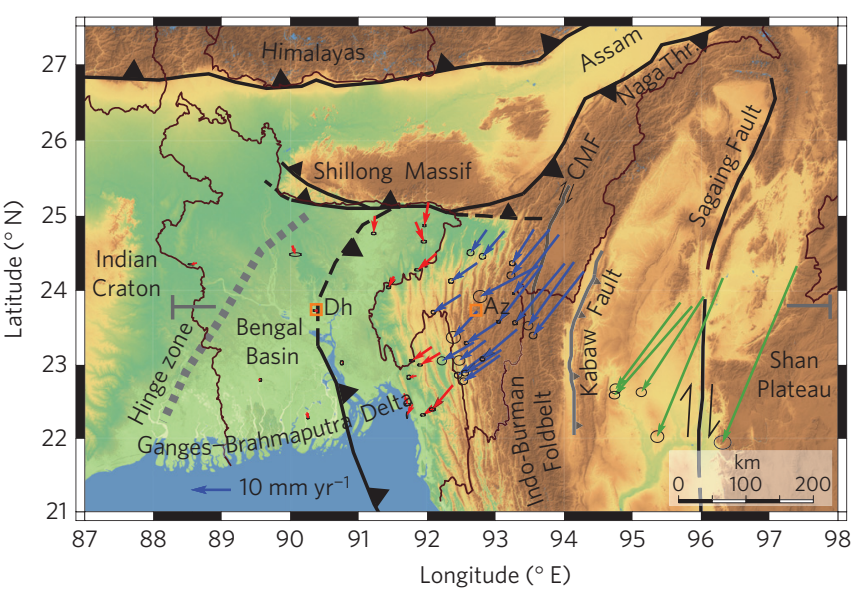

Figure 1 | Topographic map of the Ganges-Brahmaputra Delta and Indo-Burman Foldbelt showing GPS velocities. Plate boundaries and major faults are shown in black and grey, respectively. Triangles mark the surface traces of thrusts. Hinge zone indicates the edge of the Indian Craton. Arrows show GPS velocities in an Indian frame of reference. Red, blue and green arrows are new stations from Bangladesh, stations from India ${ }^{11}$, and stations from Myanmar ${ }^{9}$, respectively. Circles at the end of arrows are $2 \sigma$ uncertainties. The grey endcaps show the location of the section in Fig. 2. CMF, Churachandpur-Mao Fault; Thr., Thrust. Boxes labelled Dh and $\mathrm{Az}$ indicate Dhaka and Aizawl.

of shear parallel to it (Fig. 2). We found $\sim 21 \mathrm{~mm} \mathrm{yr}^{-1}$ of dextral motion is absorbed by the Sagaing Fault. This leaves similar rates of dextral and convergent motions to be absorbed across the rest of the boundary. The distribution of convergence is modelled well by a shallow-dipping locked megathrust below the foldbelt. It requires $17 \mathrm{~mm} \mathrm{yr}^{-1}$ if this megathrust roots all active structures across the entire boundary. A better fitting model places $\sim 13 \mathrm{~mm} \mathrm{yr}^{-1}$ on the megathrust and attributes the remainder of the shortening to the Kabaw Fault ${ }^{13}$ as a locked east-dipping oblique thrust fault, although the parameters are unconstrained. For this model, the downdip end of the locked zone of the detachment is well constrained about $25 \mathrm{~km}$ east of the Bangladesh-India border, near the boundary between the flat outer foldbelt and the steeper backstop. The depth and dip at the locking depth trade off, and thus are less well constrained. A deforming accretionary prism over an unlocked megathrust does not fit the geodetics. We interpret the results as supporting continued subduction beneath the Indo-Burman Ranges.

The dextral motion is concentrated on multiple strike-slip to oblique-slip faults. In addition to the Sagaing Fault, the $\mathrm{CMF}^{10,13}$ absorbs substantial dextral motion, $\sim 10 \mathrm{~mm} \mathrm{yr}^{-1}$. Using solely Indian data, Gahalaut et al..$^{10}$ proposed a broad dextral shear zone. They modelled $18 \mathrm{~mm} \mathrm{yr}^{-1}$ across the Indian foldbelt, with $\sim 8 \mathrm{~mm} \mathrm{yr}^{-1}$ focused on an unlocked CMF. As the downdip end of the megathrust locked zone is just inside the Indian border, most of the Indian data ${ }^{10}$ overlies the unlocked section of the detachment. The broader coverage provided by adding the Bangladeshi GPS data is more consistent with locked faults. The velocity offset between the Kabaw and Sagaing faults can be explained by $\sim 5-6 \mathrm{~mm} \mathrm{yr}^{-1}$ of dextral motion on the Kabaw Fault, but lack of coverage leaves details unconstrained. West of the CMF, we estimate $\sim 4-5 \mathrm{~mm} \mathrm{yr}^{-1}$ of dextral motion diffused across the Bangladesh network. While it is possible to ascribe this motion to the Chittagong Coastal Fault ${ }^{26}$ (CCF), we see no clear evidence of its proposed thrust component or any significant change in the structure across it. The remaining shear motion may be accommodated on the detachment or distributed across the outer foldbelt.

While the GPS data are modelled as elastic loading of a locked fault, there is considerable permanent deformation of the outer foldbelt that is presumably rooted into it. Spacing between anticlines diminishes from $\sim 20 \mathrm{~km}$ at the frontal folds to $\sim 10 \mathrm{~km}$ near Aizawl. Farther east, fold widths remain the same. This suggests active shortening of the foldbelt, with a rigid backstop somewhere between Aizawl and the CMF. This zone of active accretion correlates with our modelled locked zone. Furthermore, active accretion implies transfer of the thick sediments from the incoming lower plate to the upper plate. This necessitates advance of the detachment through time, as well as growth of the now $\sim 250-\mathrm{km}$-wide accretionary prism. Ongoing permanent deformation of the folds could accommodate some of the GPS shortening and distort the modelled elastic deformation. However, an unlocked and freely slipping detachment at the base of the tapered prism would concentrate elastic shortening towards the front of the prism, rather than in the back end of the prism, as observed (Fig. 2).

The large downdip extent to the locked zone of the detachment indicates the potential for a very large earthquake, should it rupture in a single event. We consider the updip limit to be the deformation front; since the detachment is buried by $\geq 5 \mathrm{~km}$ of low-thermal conductivity sediments, its temperature is high enough for it to be entirely in the strain-weakening regime ${ }^{27}$, and thus potentially seismogenic up to the deformation front. Recent analyses suggest that subduction zones with large thicknesses of sediments have the largest earthquakes ${ }^{28,29}$. Distortion of the plate boundary by the Shillong Massif may constitute the northern segment boundary. The southern boundary may be $\sim 200 \mathrm{~km}$ to the south at the uncertain northern end of the 1762 Arakan earthquake ${ }^{30}$. That historic earthquake killed 500 people in a much smaller Dhaka, as well as subsidence at Chittagong and coastal Bangladesh, and caused metres of uplift along the Arakan coast. Together, they suggest a rupture width $>200 \mathrm{~km}$. The potential slip in an earthquake is unknown, but $>5.5 \mathrm{~m}$ of convergence has accumulated over the past 400 years without a major earthquake, since the Mughal conquest of Bengal and the establishment of Dhaka as the regional capital. An unknown proportion of the slip is likely to be absorbed by splay faults decreasing updip megathrust slip. Given these large uncertainties, we estimate a potential earthquake of $M_{\mathrm{w}} 8.2-9.0$. Such an event would have enormous consequences for the $>140,000,000$ people living within $100 \mathrm{~km}$ of the locked megathrust in Bangladesh and India. Whether a rupture would reach the detachment tip near Dhaka, or would be shunted to the surface on a shallower splay fault farther east, could drastically impact ground shaking and destruction in that megacity. Furthermore, this megathrust earthquake potential is based on the observed geodetic motion and shallow structure of the fold belt, and is independent of mechanism(s) driving convergence.

We believe subduction is the main driver, because the boundary features all the main elements and structure of other subduction zones. The seismically active slab ${ }^{2-4,20}$ exhibits downdip extension consistent with slab pull. The N-S horizontal slab contraction ${ }^{3}$ is unusual, but is shared by the rest of the plate, and may derive from India-Asia convergence. Slab length is consistent with slab age and convergence velocity ${ }^{31}$. Most of the dextral shear is absorbed in the more rigid hinterland of the boundary zone (for example, Sagaing, Kabaw, CMF), such that the obliquity at the accretionary prism and deformation front is reduced to $\sim 21^{\circ}$ (Fig. 2 inset). This is similar to other oblique subduction zones ${ }^{31}$ where partial partitioning reduces obliquity to $<25^{\circ}$. Arc volcanism is still active in Myanmar ${ }^{3}$. Furthermore, at the Indo-Burman Ranges only a thin crust and thick sediments are entering the subduction zone. Thick continental crust that could end subduction collides only north of the Shillong Massif along the Naga segment in Assam (Fig. 1).

The most unusual aspect of the Indo-Burman subduction boundary is the thick sediment that it accretes. North of the Andaman-Sumatra subduction zone, the Sunda Arc encounters progressively more sediment, the accretionary prism becomes 

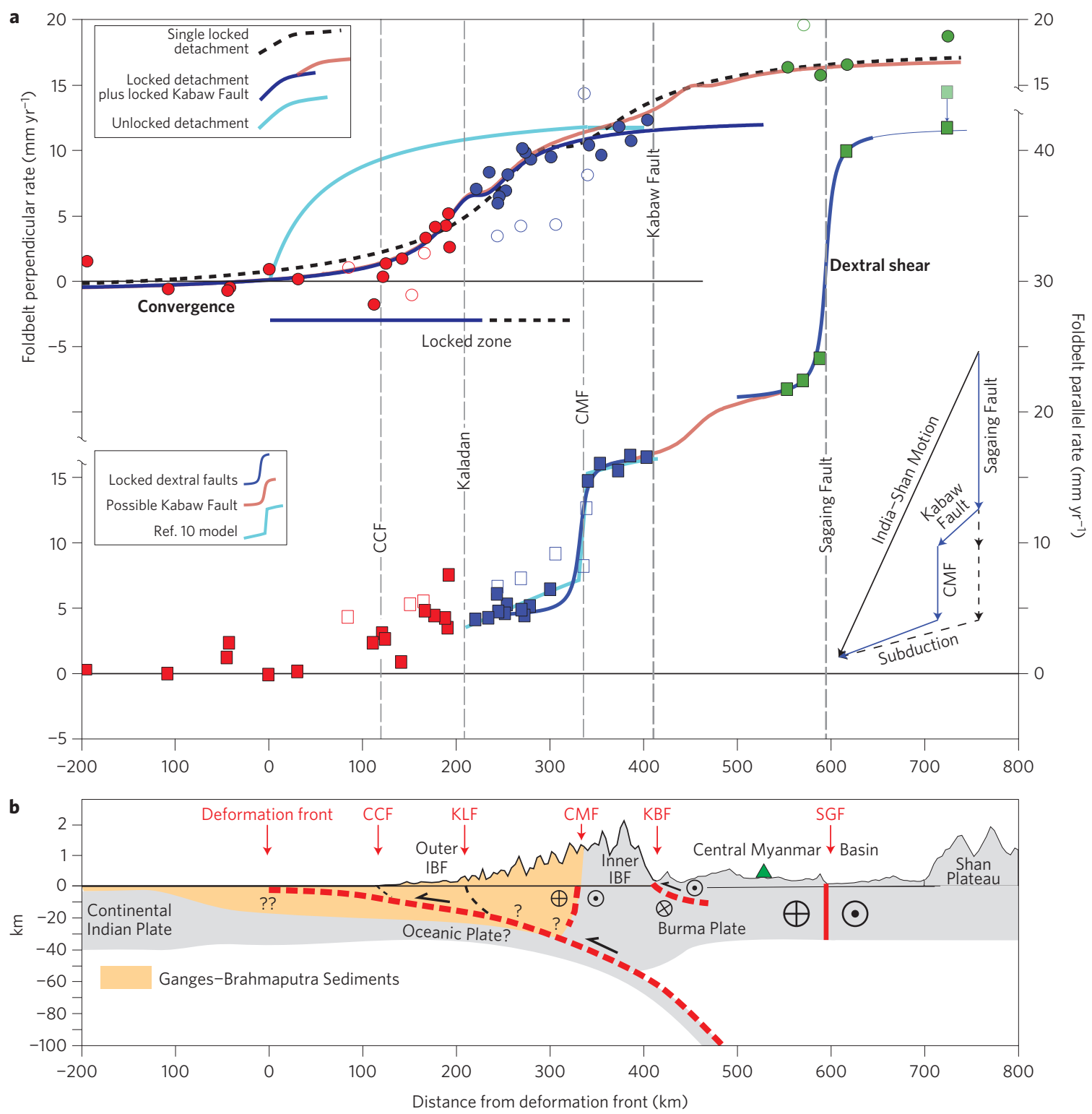

Figure 2 | Analysis of GPS velocities across Indo-Burman Ranges. a, Sections showing foldbelt perpendicular convergence (upper, circles) and parallel dextral shear (lower, squares) components of velocity field. Red, blue and green represent Bangladesh, Indian and Myanmar data, respectively. For convergence data, the black dashed line shows the best model of a single fault. The dark blue line shows the preferred model, with the light red line adding a locked Kabaw Fault. The light blue line shows the predicted velocities for an unlocked detachment. For dextral shear data, fits to elastic loading of strike-slip motion are in dark blue. A possible, unconstrained Kabaw Fault is in light red. The light blue line shows the unlocked model of Gahalaut and colleagues $^{10}$. The shear velocity of the easternmost station was adjusted for the motion of the Shan Plateau as given in ref. 9. Inset shows velocity triangles for the models. Open circles/squares were not used in modelling as discussed in the Methods section. $\mathbf{b}$. Schematic cross-section of the region indicated in Fig. 1. The modelled faults are in red with question marks indicating the poorly known deep structure of the prism. The green triangle marks the location of the volcanic arc. IBF, Indo-Burman Foldbelt; KLF, Kaladan Fault; KBF, Kabaw Fault; SGF, Sagaing Fault. Panel b modified from refs 11,13,14.

shallower and wider, and finally transitions to completely subaerial subduction at the GBD. Here, the active accretionary prism expands to $250 \mathrm{~km}$ in width within a $500-\mathrm{km}$-wide forearc. The great thickness of accreted sediment implies rapid growth of the prism and a corresponding forward advance of the detachment. Maurin and Rangin ${ }^{26}$ proposed that the outer part of the prism has advanced $200 \mathrm{~km}$ over the past 2 Myr. Despite the unusual width, its strain profile resembles those at other subduction zones with low-angle locked megathrusts. However, because of it, the size of possible earthquakes is particularly large. Furthermore, the sediments are sufficiently thick that they are probably metamorphosed and dewatered at the base. Thus, the subduction zone may be unusually hot and dry.

\section{Methods}

Methods, including statements of data availability and any associated accession codes and references, are available in the online version of this paper.

Received 2 December 2015; accepted 7 June 2016; published online 11 July 2016

\section{References}

1. Nielsen, C., Chamot-Rooke, N., Rangin, C. \& the ANDAMAN Cruise Team. From partial to full strain partitioning along the Indo-Burmese hyper-oblique subduction. Mar. Geol. 209, 303-327 (2004).

2. Le Dain, A. Y., Tapponnier, P. \& Molnar, P. Active faulting and tectonics of Burma and surrounding regions. J. Geophys. Res. 89, 453-472 (1984). 
3. Ni, J. F. et al. Accretionary tectonics of Burma and the three-dimensional geometry of the Burma subduction zone. Geology 17, 68-71 (1989).

4. Satyabala, S. P. Subduction in the Indo-Burma region: is it still active? Geophys. Res. Lett. 25, 3189-3192 (1998).

5. Rao, N. P. \& Kumar, M. R. Evidences for cessation of Indian plate subduction in the Burmese arc region. Geophys. Res. Lett. 26, 3149-3152 (1999).

6. Guzman-Speciale, M. \& Ni, J. F. Comment on "Subduction in the Indo-Burma region: is it still active?” by Satyabala, S. P. Geophys. Res. Lett. 27, 1065-1066 (2000).

7. Rangin, C., Maurin, T. \& Masson, F. Combined effects of Eurasia/Sunda oblique convergence and East-Tibetan crustal flow on the active tectonics of Burma. J. Asian Earth Sci. 76, 185-194 (2013).

8. Vigny, C. et al. Present-day crustal deformation around Sagaing Fault, Myanmar. J. Geophys. Res. 108, 2533 (2003).

9. Maurin, T., Masson, F., Rangin, C., Min, U. T. \& Collard, P. First global positioning system results in northern Myanmar: constant and localized slip rate along the Sagaing fault. Geology 38, 591-594 (2010).

10. Gahalaut, V. K. et al. Aseismic plate boundary in the Indo-Burmese wedge, northwest Sunda Arc. Geology 41, 235-238 (2013).

11. Steckler, M. S., Akhter, S. H. \& Seeber, L. Collision of the Ganges Brahmaputra Delta with the Burma Arc: implications for earthquake hazard. Earth Planet. Sci. Lett. 273, 367-378 (2008).

12. Meng, J. et al. India-Asia collision was at $24^{\circ} \mathrm{N}$ and $50 \mathrm{Ma}$ : palaeomagnetic proof from southernmost Asia. Sci. Rep. 2, 925 (2012).

13. Wang, Y., Sieh, K., Tun, S. T., Lai, K.-Y. \& Myint, T. Active tectonics and earthquake potential of the Myanmar region. J. Geophys. Res. 119, 3767-3822 (2014).

14. Murphy, R. W. \& staff of BOGMC. Bangladesh enters the oil era. Oil Gas J. 86, 76-82 (1988)

15. Lindsay, J. F., Holliday, D. W. \& Hulbert, A. G. Sequence stratigraphy and the evolution of the Ganges-Brahmaputra Delta complex. Am. Assoc. Petrol. Geol. Bull. 75, 1233-1254 (1991).

16. Curray, J. R. Geological history of the Bengal geosyncline. J. Assoc. Explor. Geophys. 12, 209-219 (1991).

17. Mitra, S., Bhattacharya, S. N. \& Nath, S. K. Crustal structure of the western Bengal Basin from joint analysis of teleseismic receiver functions and Rayleigh-wave dispersion. Bull. Seismol. Soc. Am. 98, 2715-2723 (2008).

18. Johnson, S. Y. \& Alam, A. M. N. Sedimentation and tectonics of the Sylhet trough, Bangladesh. Geol. Soc. Am. Bull. 103, 1513-1527 (1991).

19. Vernant, P. et al. Clockwise rotation of the Brahmaputra Valley relative to India: tectonic convergence in the eastern Himalaya, Naga Hills and Shillong Plateau. J. Geophys. Res. 119, 6558-6571 (2014)

20. Stork, A. L., Selby, N. D., Heyburn, R. \& Searle, M. P. Accurate relative earthquake hypocenters reveal structure of the Burma subduction zone. Bull. Seismol. Soc. Am. 98, 2815-2827 (2008).

21. Dasgupta, S. \& Nandy, D. R. Geological framework of the Indo-Burmese convergent margin with special reference to ophiolitic emplacement. Indian J Geol. 67, 110-125 (1995)

22. Uddin, A. \& Lundberg, N. Cenozoic history of the Himalayan-Bengal system: sand composition in the Bengal Basin, Bangladesh. Geol. Soc. Am. Bull. 110, 497-511 (1998)

23. Sikder, A. M. \& Alam, M. M. 2-D modelling of the anticlinical structures and structural development of the eastern fold belt of the Bengal basin, Bangladesh. Sedim. Geol. 155, 209-226 (2003).
24. Williams, L. Late Quaternary Stratigraphy and Infilling of the Meghna River Valley Along the Tectonically Active Eastern Margin of the Ganges-Brahmaputra-Meghna Delta Master's thesis, Vanderbilt Univ. Nashville (2014)

25. Socquet, A. et al. India and Sunda plates motion and deformation along their boundary in Myanmar determined by GPS. J. Geophys. Res. 111, B05406 (2006).

26. Maurin, T. \& Rangin, C. Structure and kinematics of the Indo-Burmese Wedge: recent and fast growth of the outer wedge. Tectonics $\mathbf{2 8}$, TC2010 (2009)

27. Ruff, L. J. Do trench sediments affect great earthquake occurrence in subduction zones? Pure Appl. Geophys. 129, 263-282 (1989).

28. Oleskevich, D. A., Hyndman, R. D. \& Wang, K. The updip and downdip limits to great subduction earthquakes: thermal and structural models of Cascadia, south Alaska, SW Japan, and Chile. J. Geophys. Res. 104, 14965-14991 (1999)

29. Heuret, A., Conrad, C. P., Funiciello, F., Lallemand, S. \& Sandri, L. Relation between subduction megathrust earthquakes, trench sediment thickness and upper plate strain. Geophys. Res. Lett. 39, L05304 (2012).

30. Cummins, P. R. The potential for giant tsunamigenic earthquakes in the northern Bay of Bengal. Nature 449, 75-78 (2007).

31. Jarrard, R. D. Relations among subduction zone parameters. Rev. Geophys. 24, 217-284 (1986)

\section{Acknowledgements}

We thank R. Bürgmann for comments that helped to improve the paper. We thank J. Armbruster, who installed the initial 6 stations in 2003, and N. Feldl, who helped install 12 stations in 2007 . We also thank the Dhaka University students who helped maintain the GPS network and the people at the many sites that host the GPS stations. Without their efforts and UNAVCO support, this project would not have been possible. We thank M. Kogan for help with processing. We thank C. Rangin, F. Masson and T. Maurin for sharing their Myanmar GPS data with us. This material is based on equipment and engineering services provided by the UNAVCO Facility with support from the National Science Foundation (NSF) and National Aeronautics and Space Administration (NASA) under NSF Cooperative Agreement EAR-0735156. This project was supported by NSF INT 99-00487, NSF EAR-06 36037 and NSF IIA 09-68354. L.F. and E.M.H. were supported by Singapore National Research Foundation Fellowship number NRF-NRFF2010-064. Lamont-Doherty Earth Observatory publication number 8204

\section{Author contributions}

M.S.S. planned the paper. D.R.M. did the model analysis with assistance from L.F. and E.M.H., while S.H.A processed the GPS data. J.G. and M.H. contributed to the data projections. M.S.S., S.H.A., D.R.M. and L.S. installed and maintained the GPS network. All authors discussed the results and contributed to writing the manuscript.

\section{Additional information}

Supplementary information is available in the online version of the paper. Reprints and permissions information is available online at www.nature.com/reprints. Correspondence and requests for materials should be addressed to M.S.S.

\section{Competing financial interests}

The authors declare no competing financial interests. 


\section{Methods}

Methods for GPS data analysis and modelling. Merging data sets. In 2003, we installed six Trimble 4000ssi receivers, which were broadly distributed around Bangladesh. In 2007, we installed 12 Trimble NetRS with UNAVCO, concentrated in eastern Bangladesh. Additional receivers installed in 2012-2014 were not used due to their short time series. Due to lack of basement outcrop, antennas were installed on threaded stainless steel rods cemented or epoxied into reinforced concrete buildings. All Bangladesh sites have continuous recordings (red symbols in Figs 1 and 2). Campaign stations in Myanmar were occupied in 2005 and $2008^{9}$ (green symbols in Figs 1 and 2). Daily RINEX files from the Bangladesh and Myanmar networks were processed together using GAMIT/GLOBK ${ }^{32,33}$. For the Indian network (blue symbols in Figs 1 and 2) only processed velocities were available. We therefore stabilized the Bangladesh/Myanmar velocities with the same set of IGS (International GNSS Service) stations that were used by Gahalaut et al. ${ }^{10}$ to minimize reference bias. We converted the Indian velocities to ITRF $2008^{34}$ and performed a Helmert transformation to minimize the velocity differences at the IGS stations and place all data into the same reference framework. Supplementary Figs 1 and 2 reproduce Figs 1 and 2 with the four-letter GPS site labels. Velocities are in Supplementary Table 1.

Indian Plate pole. The rotation of the Indian Plate is the least well known of all major plates; data available from the northern part of the plate away from deformation associated with the Himalayas are limited. Mahesh et al. ${ }^{35}$ addressed this issue by determining a new pole using 13 broadly distributed sites across India. However, none of their sites are within $700 \mathrm{~km}$ of our network, and we observed a systematic $\sim 2 \mathrm{~mm} \mathrm{yr}^{-1}$ residual velocity for Bangladeshi sites on stable India. We therefore calculated a new pole for the Indian Plate. We performed a Helmert transformation between the two data sets. Then we calculated a new pole by combining sites DHAK and RAJS with the 13 sites from Mahesh and colleagues ${ }^{35}$. After modelling, we found that both DHAK and RAJS were offset from the best fitting elastic dislocation model by $\sim 1 \mathrm{~mm} \mathrm{yr}^{-1}$. We therefore recomputed the pole to allow for this shift. The mean residual velocity was $0.78 \mathrm{~mm} \mathrm{yr}^{-1}$, similar to the value of $0.76 \mathrm{~mm} \mathrm{yr}^{-1}$ obtained by Mahesh and colleagues ${ }^{35}$. Only two stations had a residual greater than $1 \mathrm{~mm} \mathrm{yr}^{-1}$. The new pole obtained is at $51.42^{\circ} \mathrm{N} 2.10^{\circ} \mathrm{E}$ with a rotation rate of $0.5146^{\circ} \mathrm{Myr}^{-1}$. It is slightly west of the pole of $51.4^{\circ} \mathrm{N} 8.9^{\circ} \mathrm{E}$ with a rotation rate of $0.539^{\circ} \mathrm{Myr}^{-1}$ obtained by Mahesh et al. ${ }^{35}$, and close to the one obtained by Banerjee and colleagues ${ }^{36}$. It lies between those poles and other published values ${ }^{25,36-38}$ (Supplementary Table 2).

Projection. Figure 1 shows the velocities at the stations in our Indian frame of reference. We chose to model the velocities along a section perpendicular to the foldbelt, and to project velocities parallel and perpendicular to the curved forearc. However, the curvature of the foldbelt changes across its length (Supplementary Fig. 3). The northward growth of the accretionary prism of the Indo-Burman Foldbelt, in conjunction with its collision with the Shillong Massif, result in the divergence of the small circles that fit the eastern side of the foldbelt. The rigid backstop and the earthquakes of the Wadati-Benioff zone are fitted well by a small circle centred at $22.5^{\circ} \mathrm{N}$ and $99.8^{\circ} \mathrm{E}$. For the frontal foldbelt, we constructed a smooth surface for projecting velocities based on fold morphology. We used the segment boundaries, which are aligned in a quasi-radial pattern, as guides for detachment kinematics. Making our projection curves normal to the segment boundaries allows for the possibility that the folds themselves are oblique to the shortening direction. This is certainly the case in the northernmost part of the foldbelt, where the deformation is affected by the interaction with the Shillong Massif. For the few stations at the transition, we averaged the directions associated with the two projections (Supplementary Fig. 3).

Station selection. We only utilized stations from Gahalaut et al..$^{10}$ south of $25.1^{\circ} \mathrm{N}$ to differentiate the region north of the Dauki Fault, where continent-continent collision is occurring along the Naga and Haflong thrust system, from the region to the south, where subduction of the GBD is occurring. During the analysis we noticed that additional stations slightly farther south deviated from the main trend of the data set. These include JAML, SUST, JAFL in Bangladesh and KASH, JIRI, AWNG and KJRK in India (Supplementary Fig. 2). We interpret this as due to an additional component of motion from the overthrusting of Shillong Massif along the Dauki Fault. It continues to the east, where the foldbelt is thrust over the Shillong Massif, and implies active continuation of the Dauki Fault beneath the foldbelt. By KJRK, the deviation decreases, and it is not seen at IMPH. It is unknown if the Dauki Fault ceases activity or is too deep to affect the surface velocities. SUST also shows an additional motion that may be due to its position on the active Sylhet anticline. HENG shows a clockwise rotation that is probably due to block rotation within the CMF fault zone, so it was also excluded.

Elastic dislocation model. We model the foldbelt perpendicular velocities as deformation associated with a locked dipping thrust ${ }^{39}$ using GTdef ${ }^{40}$. Since the locked zone buttresses the shallow part of the megathrust, the shallow megathrust tip is modelled as locked ${ }^{41}$. We initially modelled the entire transect as a single locked fault (Fig. 2 and Supplementary Fig. 2). We then made the model more realistic by allowing for possible contributions from structures in the upper plate, specifically the Kabaw Fault ${ }^{13}$. This yields a significant improvement in the fit, with residuals of $<1.1 \mathrm{~mm} \mathrm{yr}^{-1}$. We use a fit to the boundary between the seismicity in the lower plate and the upper plate as a guide for the subduction zone dip, with a best fit of $\sim 7.3^{\circ}$ at the locking depth. The downdip end of the locked fault is located on the kink of the blue curve (Fig. 2 and Supplementary Fig. 2) near MAMT at $\mathrm{km} 225$. For all dips $>6^{\circ}$, the detachment must flatten westwards towards the blind deformation front near Dhaka, while dips $>10^{\circ}$ are inconsistent with seismicity. We therefore include deviation from the best estimate of slab dip from seismicity in the misfit calculation. Misfits are presented in Supplementary Fig. 4. The horizontal location of the downdip end of the locked zone is well constrained. The depth of $25 \mathrm{~km}$ is probably model dependent.

The dextral velocities at the CMF and Sagaing Faults are fitted by 10 and $21 \mathrm{~mm} \mathrm{yr}^{-1}$ of strike-slip, respectively. The Sagaing Fault uses the locking depth of $6.3 \mathrm{~km}$ determined by Maurin et al. (2010). The shear velocity of BHAM was adjusted for the motion of the Shan Plateau as given in Maurin and colleagues 9 . For the CMF, we used the same locking depth. While there is insufficient data to constrain the Kabaw Fault, a $30^{\circ}$-dipping fault with $5.5 \mathrm{~mm} \mathrm{yr}^{-1}$ dip slip and $5 \mathrm{~mm} \mathrm{yr}^{-1}$ strike-slip (that is, rake $=42^{\circ}$ ) explains the shifts between the India and Myanmar velocities. The velocity field does not require activity on the Chittagong Coastal Fault (CCF) and Kaladan Fault, so they are not included in the modelling.

Unlocked detachment. For an unlocked detachment, the strata above the blind detachment must be inducing shortening of the accretionary prism sediments. We model this as shortening of a sediment wedge whose thickness increases from $a=5 \mathrm{~km}$ near the deformation to $b=35 \mathrm{~km}$ near the backstop $L=340 \mathrm{~km}$, farther east near the CMF. The strain rate for a linear increase in thickness is equal to $\int_{0}^{x} \dot{\varepsilon}_{\max } a b \cdot[a+((b-a) x / L)]^{-2} \mathrm{~d} x=\left(\dot{\varepsilon}_{\max } a b L /[(a-b)(a(L-x)+b x)]\right)$ $-\left(\dot{\varepsilon}_{\max } a b L /[(a-b)(a L)]\right)$. Since the compliance of the thin frontal edge of the wedge is greater than the thicker part near the backstop, most of the deformation is concentrated there (Fig. 2). We modelled deformation with a linear wedge; a curved basal detachment or stiffer strata towards the east would focus even more deformation towards the front. This predicts a significantly different pattern than that from a locked detachment.

We also calculated the deformation for elastic loading of a detachment that is unlocked from the deformation front eastwards with the detachment initiating at $5 \mathrm{~km}$ depth. This produced elastic deformation centred on the deformation front. This yields an even worse fit to the geodetic data than the shortening model shown on Fig. 2. Thus, for either model of an unlocked detachment, elastic deformation is centred around the updip end of the megathrust. This contrasts with a locked detachment, where deformation is focused at the downdip end of the locked zone, consistent with the GPS data.

Data and code availability. Daily RINEX files of the GPS data from Bangladesh used in the models are available through UNAVCO (http://www.unavco.org). Other data supporting the findings of this paper are available in the article and its Supplementary Information file. Publicly available codes were used for data processing and analysis as indicated in this paper. Any additional information is available from the corresponding author on request.

\section{References}

32. Herring, T. A., King, R. W. \& McClusky, S. C. GAMIT Reference Manual, Release 10.4 (Massachusetts Institute of Technology Department of Earth, Atmospheric, and Planetary Sciences, 2010).

33. Herring, T. A., King, R. W. \& McClusky, S. C. GLOBK Reference Manual, Global Kalman Filter VLBI and GPS Analysis Program, Release 10.4 (Massachusetts Institute of Technology Department of Earth, Atmospheric, and Planetary Sciences, 2010).

34. Altamimi, Z., Collilieux, X. \& Métivier, L. ITRF2008: an improved solution of the International Terrestrial Reference Frame. J. Geod. 85, 457-473 (2011).

35. Mahesh, P. et al. Rigid Indian plate: constraints from GPS measurements. Gondwana Res. 22, 1068-1072 (2012).

36. Banerjee, P., Bürgmann, R., Nagarajan, B. \& Apel, E. Intraplate deformation of the Indian subcontinent. Geophys. Res. Lett. 35, L18301 (2008).

37. Jade, S. et al. Estimates of interseismic deformation in Northeast India from GPS measurements. Earth Planet. Sci. Lett. 263, 221-234 (2007).

38. Bettinelli, P. et al. Plate motion of India and interseismic strain in the Nepal Himalaya from GPS and DORIS measurements. J. Geod. 80, 567-589 (2006).

39. Okada, Y. Internal deformation due to shear and tensile faults in a half-space. Bull. Seismol. Soc. Am. 82, 1018-1040 (1992).

40. Feng, L. et al. Active deformation near the Nicoya Peninsula, Northwestern Costa Rica, between 1996 and 2010: interseismic megathrust coupling. J. Geophys. Res. 117, B06407 (2012).

41. Wang, K. \& Dixon, T. "Coupling" semantics and science in earthquake research. Eos Trans. AGU 85, 180-181 (2004). 


\section{Methods for GPS Data Analysis and Modeling}

Merging Datasets. In 2003, we installed 6 Trimble 4000ssi receivers that were broadly distributed around Bangladesh. In 2007, we installed 12 Trimble NetRS with UNAVCO, concentrated in eastern Bangladesh. Additional receivers installed in 2012-2014 were not used due to their short time series. Due to lack of basement outcrop, antennas were installed on threaded stainless steel rods cemented or epoxied into reinforced concrete buildings. All Bangladesh sites have continuous recordings (red symbols in Figs. 1 and 2). Campaign stations in Myanmar were occupied in 2005 and $2008^{9}$ (green symbols in Figs. 1 and 2). Daily RINEX files from the Bangladesh and Myanmar networks were processed together using GAMIT/GLOBK ${ }^{31,32}$. For the Indian network (Blue symbols in Figs. 1 and 2) only processed velocities were available. We therefore stabilized the Bangladesh/Myanmar velocities with the same set of IGS stations that were used by Gahalaut et al. ${ }^{10}$ to minimize reference bias. We converted the Indian velocities to ITRF $2008^{33}$ and performed a Helmert transformation to minimize the velocity differences at the IGS stations and place all data into the same reference framework. Velocities are in Table S1.

Indian plate pole. The rotation of the Indian plate is the least well known of all major plates; data available from the northern part of the plate away from deformation associated with the Himalayas are limited. Mahesh et al. ${ }^{34}$ addressed this issue by determining a new pole using 13 broadly distributed sites across India. However, none of their sites are within $700 \mathrm{~km}$ of our network and we observed a systematic $\sim 2 \mathrm{~mm} / \mathrm{y}$ residual velocity for Bangladeshi sites on stable India. We therefore calculated a new pole for the Indian plate. We performed a Helmert transformation between the two data sets. Then we calculated a new pole by combining DHAK and RAJS with the 13 sites from Mahesh et al. ${ }^{34}$. After modeling, we found that both DHAK and RAJS were offset from the best fitting elastic dislocation model by $\sim 1 \mathrm{~mm} / \mathrm{yr}$. We therefore recomputed the pole to allow for this shift. The mean residual velocity was $0.78 \mathrm{~mm} / \mathrm{y}$, similar to the value of $0.76 \mathrm{~mm} / \mathrm{y}$ obtained by Mahesh et al. ${ }^{34}$. Only two stations had a residual greater than $1 \mathrm{~mm} / \mathrm{yr}$. The new pole obtained is at $51.42^{\circ} \mathrm{N} 2.10^{\circ} \mathrm{E}$ with a rotation rate of $0.5146^{\circ} / \mathrm{my}$. It is slightly west of the pole of $51.4^{\circ} \mathrm{N} 8.9^{\circ} \mathrm{E} 0.539^{\circ} / \mathrm{my}$ obtained by Mahesh et al. ${ }^{34}$, and close to the one obtained by Banerjee et al. ${ }^{35}$. It lies between those poles and other published values ${ }^{24,35-37}$ (Table S2).

Projection. Fig. 1 shows the velocities at the stations in our Indian frame of reference. We chose to model the velocities along a section perpendicular to the foldbelt and project velocities parallel and perpendicular to the curved forearc. However, the curvature of the foldbelt changes across its length (Fig. S1). The northward growth of the accretionary prism of the Indo-Burman Foldbelt, in conjunction with its collision with the Shillong Massif, result in the divergence of the small circles that fit the eastern side of the foldbelt. The rigid backstop and the earthquakes of the Wadati-Benioff zone are well fit by a small circle centered at $22.5^{\circ} \mathrm{N}$ and $99.8^{\circ} \mathrm{E}$. For the frontal foldbelt, we constructed a smooth surface for projecting velocities based on fold morphology. We used the segment boundaries, which are aligned in a quasi-radial pattern, as guides for detachment kinematics. Making our projection curves normal to the segment boundaries allows for the possibility that the folds themselves are oblique to the shortening direction. This is certainly the case in the northernmost part of the foldbelt where the deformation is affected by the interaction with Shillong. For the few stations at the transition, we averaged the directions associated with the two projections (Fig. S1).

Station selection. We only utilized stations from Gahalaut et al. ${ }^{10}$ south of $25.1^{\circ} \mathrm{N}$ to differentiate the region north of the Dauki Fault, where continent-continent collision is occurring along the 
Naga and Haflong thrust system, from the region to the south, where subduction of the GBD is occurring. During the analysis we noticed that additional stations slightly farther south deviated from the main trend of the data set. These include JAML, SUST, JAFL in Bangladesh and KASH, JIRI, AWNG and KJRK in India. We interpret this as due to an additional component of motion from the overthrusting of Shillong along the Dauki Fault. It continues to the east where the foldbelt is thrust over Shillong and implies a continuation of the Dauki Fault beneath the foldbelt. By KJRK, the deviation decreases and it is not seen at IMPH. It is unknown if the Dauki ceases activity or is too deep the affect the surface velocities. SUST also shows an additional motion that may be due to its position on the active Sylhet anticline. HENG shows a clockwise rotation that is likely due to block rotation within the CMF fault zone, so it was also excluded.

Elastic Dislocation Model. We model the foldbelt perpendicular velocities as deformation associated with a locked dipping thrust ${ }^{38}$ using GTdef ${ }^{39}$. Since the locked zone buttresses the shallow part of the megathrust, the shallow megathrust tip is modeled as locked ${ }^{40}$. We initially modeled the entire transect as a single locked fault (Fig. 2). We then made the model more realistic by allowing for possible contributions from structures in the upper plate, specifically the Kabaw Fault ${ }^{13}$. This yields a significant improvement in the fit with residuals of $<1.1 \mathrm{~mm} / \mathrm{y}$. We use a fit to the boundary between the seismicity in the lower plate and the upper plate as a guide for the subduction zone dip with a best fit of $\sim 7.3^{\circ}$ at the locking depth. The downdip end of the locked fault is located on the kink of the blue curve (Fig. 2; S2) near MAMT at km 225. For all dips $>6^{\circ}$, the detachment must flatten westward towards the blind deformation front near Dhaka, while dips $>10^{\circ}$ are inconsistent with seismicity. We therefore include deviation from the best estimate of slab dip from seismicity in the misfit calculation. Misfits are presented in Figure S2. The horizontal location of the down dip end of the locked zone is well constrained. The depth of $25 \mathrm{~km}$ is likely model dependent.

The dextral velocities at the CMF and Sagaing Faults are fit by 10 and $21 \mathrm{~mm} / \mathrm{y}$ of strike-slip, respectively. The Sagaing Fault uses the locking depth of $6.3 \mathrm{~km}$ determined by Maurin et al. (2010). The shear velocity of BHAM was adjusted for the motion of the Shan Plateau as given in Maurin et al. ${ }^{9}$. For the CMF, we used the same locking depth. While there is insufficient data to constrain the Kabaw Fault, a $30^{\circ}$-dipping fault with $5.5 \mathrm{~mm} / \mathrm{yr}$ dip slip and $5 \mathrm{~mm} / \mathrm{yr}$ strike-slip (i.e., rake $=42^{\circ}$ ) explains the shifts between the India and Myanmar velocities. The velocity field does not require activity on the Chittagong Coastal Fault (CCF) and Kaladan Fault so they are not included in the modeling.

Unlocked detachment. For an unlocked detachment, the strata above the blind detachment must be inducing shortening of the accretionary prism sediments. We model this as shortening of a sediment wedge whose thickness increases from $\mathrm{a}=5 \mathrm{~km}$ near the deformation from to $\mathrm{b}=35 \mathrm{~km}$ near the backstop $\mathrm{L}=340 \mathrm{~km}$ farther east near the $\mathrm{CMF}$. The strain rate for a linear increase in thickness is equal to $\int_{0}^{x} \dot{\varepsilon}_{\text {max }} a b \cdot\left[a+\frac{(b-a) x}{L}\right]^{-2} d x=\frac{\dot{\varepsilon}_{\text {max }} a b L}{[(a-b)(a(L-x)+b x)]}-\frac{\dot{\varepsilon}_{\text {max }} a b L}{[(a-b)(a L)]}$. Since the compliance of the thin frontal edge of the wedge is greater than the thicker part near the backstop, most of the deformation is concentrated there (Fig. 2). We modeled deformation with a linear wedge; a curved basal detachment or stiffer strata towards the east would focus even more deformation towards the front. This predicts a significantly different pattern than that from a locked detachment. 
We also calculated the deformation for elastic loading of a detachment that is unlocked from the deformation front eastward with the detachment initiating at $5 \mathrm{~km}$ depth. This produced elastic deformation centered on the deformation front. This yields an even a worse fit to the geodetic data than the shortening model shown on Figure 2. Thus for either model of an unlocked detachment, elastic deformation is centered around the updip end of the megathrust. This contrasts with a locked detachment where deformation is focused at the downdip end of the locked zone, consistent with the GPS data.

Data and code availability. Daily RINEX files of the GPS data from Bangladesh used in the models are available through UNAVCO (http://www.unavco.org). Other data supporting the findings of this paper are available in the article and its supplementary information file. Publically available codes were used for data processing and analysis as indicated in paper. Any additional information is available from the corresponding author upon request.

\section{Additional References for Method Section}

31. Herring, T. A., King, R. W., and McClusky, S. C., GAMIT reference manual, release 10.4. Massachusetts Institute of Technology Department of Earth, Atmospheric, and Planetary Sciences, Cambridge, 171 p. (2010a)

32. Herring, T.A., King, R.W., and McClusky, S.C., GLOBK reference manual, Global Kalman filter VLBI and GPS analysis program, release 10.4. Massachusetts Institute of Technology Department of Earth, Atmospheric, and Planetary Sciences, Cambridge, 95 p. (2010b)

33. Altamimi Z., Collilieux, X., Métivier, L. ITRF2008: an improved solution of the International Terrestrial Reference Frame, J. Geodesy, 85, 457-473, doi:10.1007/s00190-011-0444-4 (2011)

34. Mahesh P., Catherine, J. K., Gahalaut, V. K., Kundu, B., Ambikapathy, A., Bansal, A., Premkishore, L., Narsaiah, M., Ghavri, S., Chadha, R. K., Choudhary, P., Singh, D. K., Singh, S.K., Kumar, S., Nagarajan, B., Bhatt, B. C., Tiwari, R. P., Kumar, A., Kumar, A., Bhu, H. Kalita S. Rigid Indian plate: Constraints from GPS measurements, Gondwana Research 22, 1068-1072, doi:10.1016/j.gr.2012.01.011 (2012)

35. Banerjee, P., Bürgmann, R., Nagarajan, B., and Apel, E. Intraplate deformation of the Indian subcontinent: Geophys. Res. Lett., 35, L18301, doi: 10.1029/2008GL035468 (2008)

36. Jade, S., Mukul, M., Bhattacharyya, A. K., Vijayan, M. S. M., Jaganathan, S., Kumar, A., Tiwari, R. P., Kumar, A., Kalita, S., Sahu, S. C., Krishna, A.,P., Gupta, S.,S., Murthy, M. V. R. L., Gaur V. K. Estimates of interseismic deformation in Northeast India from GPS measurements, Earth Planet. Sci. Lett., 263, 221-234, doi:10.1016/j.eps1.2007.08.031 (2007),

37. Bettinelli, P., Avouac, J. P., Flouzat, M., Jouanne, F., Bollinger, L., Willis, P., Chitrakar, G. R. Plate motion of India and interseismic strain in the Nepal Himalaya from GPS and DORIS measurements. J. Geod. 80, 567-589 (2006).

38. Okada, Y. Internal deformation due to shear and tensile faults in a half-space. Bull. Seismol. Soc. Amer. 82, 1018-1040 (1992).

39. Feng, L., Newman, A. V., Protti, J. M., González, V., Jiang, Y., Dixon T. H. Active Deformation near the Nicoya Peninsula, Northwestern Costa Rica, Between 1996 and 2010: Interseismic megathrust coupling, J. Geophys. Res., 117, B06407, doi:10.1029/2012JB009230 (2012).

40. Wang, K. and Dixon, T. "Coupling” semantics and science in earthquake research, Eos Trans. $A G U, \mathbf{8 5}, 180-181$ (2004). 